\title{
Abdominal ultrasonographic manifestations in pediatric patients with tuberous sclerosis complex
}

\author{
Zhihua $\mathrm{Xu}^{1 \# \wedge}$, Junbo $\mathrm{Wu}^{2 \#}$, Guimin $\mathrm{Xu}^{3}$, Hongxia Luo ${ }^{1 \wedge}$ \\ ${ }^{1}$ Department of Ultrasonic Diagnosis, The Second Affiliated Hospital and Yuying Children's Hospital, Wenzhou Medical University, Wenzhou, \\ China; ${ }^{2}$ Department of Ultrasound Imaging, Wuhan Children's Hospital (Wuhan Maternal and Child Healthcare Hospital), Tongji Medical College, \\ Huazhong University of Science and Technology, Wuhan, China; ${ }^{3}$ Department of Anesthesia, The Second Affiliated Hospital and Yuying Children's \\ Hospital, Wenzhou Medical University, Wenzhou, China \\ Contributions: (I) Conception and design: Z Xu, H Luo; (II) Administrative support: H Luo; (III) Provision of study materials or patients: J Wu, H \\ Luo; (IV) Collection and assembly of data: J Wu, G Xu; (V) Data analysis and interpretation: Z Xu, G Xu; (VI) Manuscript writing: All authors; (VII) \\ Final approval of manuscript: All authors. \\ \#These authors contributed equally to this work. \\ Correspondence to: Hongxia Luo. Department of Ultrasonic Diagnosis, The Second Affiliated Hospital and Yuying Children's Hospital, Wenzhou \\ Medical University, No. 109 Xueyuan West Road, Lucheng District, Wenzhou 325000, China. Email: luohongxia0127@163.com.
}

\begin{abstract}
Background: Tuberous sclerosis complex (TSC) is a rare genetic disease which leads to formation of benign tumors in the brain and other organs of the body. Ultrasound (US) can detect the location, quantity, size and internal echo of TSC-associated renal diseases, liver angiomyolipoma (AML), and coexisting lesions, providing important diagnostic basis for clinical diagnosis. The aim of the present study was to investigate the abdominal ultrasonographic features of pediatric TSC and explore the advantages of abdominal ultrasonography in clinical practice.
\end{abstract}

Methods: Data of children with TSC, who presented to the Second Affiliated Hospital and Yuying Children's Hospital, Wenzhou Medical University, between January 2016 and November 2018, were analyzed by a retrospective chart review. The cases were identified from electronic medical records (EMR) system and underwent ultrasonography, we yielded a total of 12 patients.

Results: The 12 pediatric patients, including 5 boys and 7 girls, ranged in age from 9 months to 13 years old. And they all had a history of epilepsy. All the patients underwent brain magnetic resonance imaging (MRI) or computed tomography (CT) examination, which revealed a scattered distribution of multiple hyperintense nodules. Of the 12 patients, 10 had TSC-associated bilateral renal AMLs, 5 had hepatic AML, and 4 had renal cysts.

Conclusions: US is a useful and non-invasive tool for the detection of TSC-associated renal and liver lesions and for clinical follow-up among pediatric patients.

Keywords: Tuberous sclerosis complex (TSC); ultrasound (US); angiomyolipoma (AML); pediatric patients

Submitted May 29, 2020. Accepted for publication Nov 15, 2020.

doi: $10.21037 / \mathrm{tp}-20-150$

View this article at: http://dx.doi.org/10.21037/tp-20-150

\section{Introduction}

Tuberous sclerosis complex (TSC) is a rare autosomal dominant, multisystem neurocutaneous syndrome that can affect the brain, eyes, heart, kidneys, lungs, and skin. TSC is also one of the leading causes of severe central neural system disorders, epilepsy, mental retardation, and autism

^ ORCID: Zhihua Xu: 0000-0001-9225-892X; Hongxia Luo: 0000-0002-5894-0359. 
among children $(1,2)$. The prevalence of TSC is estimated to be 1:6,000 live births (3). Neural manifestations play an extremely important role in disease prognosis and progression among pediatric TSC patients, with a prevalence of up to $90 \%$ (4). However, recent studies have increasingly recognized new phenotypes of TSC without neural conditions but involving other vital organs, such as TSC-associated renal diseases, liver angiomyolipoma (AML), and co-existing lesions $(1,5,6)$.

A cross-sectional study showed that the prevalence of renal involvement in TSC was 61\%; AMLs were detected in $49 \%$ of pediatric patients, renal cysts in $32 \%$, and renal carcinoma in $2.2 \%$. In children $<5$ years, cysts were found to be more common than AML (7). A study of pediatric TSC patients in South-East Asia showed that that the prevalence of renal involvement was $43.5 \%$; of the renal involvement cases, the prevalence of AML was about $60 \%$, renal cysts was about $50 \%$, and 1 case had suspected renal cell carcinoma (8).

AML occurs in the kidneys and the liver. In an analysis of a large cohort from three sites, hepatic AMLs were observed in 7\% of TSC individuals (9). In smaller studies, which included mostly adult patients, AMLs have been observed in $45 \%$ of participants with TSC $(10,11)$. Hepatic AMLs have been found to coexist with renal lesions in the majority of reported cases $(10,12)$.

Renal AMLs are considered to be the primary cause of morbidity and mortality in TSC patients (13). They can lead to complications, such as hemorrhage, pain, and impaired renal function (14). Yu et al. and Okada et al. suggested that the presence of cystic disease is the major predisposing factor in the development of renal failure in people with TSC $(15,16)$.

In contrast to renal lesions, hepatic AMLs are predominantly asymptomatic, non-progressive lesions (6). In a large study of 355 patients at Mayo Clinic, hepatic hamartomas were not mentioned as a possible cause of death in patients with TSC (13). However, in a previously published study, a patient with TSC and hepatic AML, which spontaneously ruptured with subsequent hemorrhage, was reported (17).

These lesions including renal AML, liver AML and renal cysts are usually identified incidentally at a relatively older age, which increases the risk of poor prognosis (6). Therefore, early detection and awareness of multisystem disorders, may help to improve the clinical management of pediatric TSC patients.
Ultrasound (US) is a well-established, non-invasive imaging tool for investigating pediatric abdominal diseases due to its superiority in soft tissue characterization and operation convenience (18).

A questionnaire study showed that US was the most frequent imaging modality used for renal manifestations of TSC in France and Norway (19).

Rakowski et al. recommended renal US at baseline for all children with TSC under the age of 5 years, and if normal, rescreening after 2-3 years (20). If an AML or cyst is suggested by imaging, then US screening should be performed annually.

According to an International Working Group Consensus statement, US is the preferred examination method in most pediatric patients with cystic kidney diseases or simple cysts (21). Magnetic resonance imaging (MRI) usually requires sedation in young children, which poses extra risks; US yields adequate information in most children with kidney cysts. Computed tomography (CT) should not be routinely used for the investigation of pediatric kidney cysts, because US and MRI usually provide better contrast resolution without radiation exposure. Most renal AMLs also can be diagnosed by ultrasonography showing hyperechoic images due to the presence of adipose tissue in the tumor (22).

Current [2012] surveillance and management guidelines do not mention liver monitoring (18). Jóźwiak et al. suggested that an abdominal US examination be performed each year, with a special focus on the kidneys and liver (6).

The aim of the present study was to analyze the abdominal ultrasonographic manifestations in the kidneys and liver of pediatric TSC patients, which have not been well studied in the literature compared with the central neural system. We present the following article in accordance with the STROBE reporting checklist (available at http://dx.doi.org/10.21037/tp-20-150).

\section{Methods}

\section{Patients}

The present retrospective study was conducted in accordance with the Declaration of Helsinki (as revised in 2013), and the study was approved by Institutional Review Board of the Second Affiliated Hospital of Wenzhou Medical University (No. LCKY-230), and the requirement for informed consent from the patients was waived. We reviewed medical records and searched for TSC patients 
Table 1 Clinical data of eight children with TSC

\begin{tabular}{|c|c|c|c|c|c|}
\hline Case & Gender & Age & Skin & Epilepsy & Development retardation \\
\hline 2 & Male & 2 years & Pigment loss spot & Yes & Yes \\
\hline 3 & Male & 13 years & Pigment loss spot & Yes & Yes \\
\hline 4 & Female & 11 years & Pigment loss spot & Yes & Yes \\
\hline \multirow[t]{2}{*}{5} & \multirow[t]{2}{*}{ Female } & \multirow[t]{2}{*}{11 years } & Pigment loss spot & \multirow[t]{2}{*}{ Yes } & \multirow[t]{2}{*}{ Yes } \\
\hline & & & Facial angiofibroma & & \\
\hline \multirow[t]{2}{*}{6} & \multirow[t]{2}{*}{ Female } & \multirow[t]{2}{*}{3 years } & Pigment loss spot & \multirow[t]{2}{*}{ Yes } & \multirow[t]{2}{*}{ Yes } \\
\hline & & & Facial angiofibroma & & \\
\hline \multirow[t]{2}{*}{8} & \multirow[t]{2}{*}{ Female } & \multirow[t]{2}{*}{10 years } & Pigment loss spot & \multirow[t]{2}{*}{ Yes } & \multirow[t]{2}{*}{ Yes } \\
\hline & & & Facial angiofibroma & & \\
\hline 9 & Male & 3 years & Pigment loss spot & Yes & None \\
\hline 10 & Female & 11 months & None & Yes & None \\
\hline \multirow[t]{2}{*}{11} & \multirow[t]{2}{*}{ Female } & \multirow[t]{2}{*}{13 years } & Pigment loss spot & \multirow[t]{2}{*}{ Yes } & \multirow[t]{2}{*}{ Yes } \\
\hline & & & Facial angiofibroma & & \\
\hline 12 & Male & 9 years & Pigment loss spot & Yes & None \\
\hline
\end{tabular}

TSC, tuberous sclerosis complex.

in the electronic medical records (EMR) system which was conducted using the terms pediatric, TSC, and reviewed the pediatric patients' ultrasonography in the PACS. Twelve pediatric patients who were diagnosed with TSC in our hospital between January 2016 and November 2018 were enrolled. The diagnosis of TSC met the clinical diagnostic criteria revised by the International TSC Consensus Conference in 2012 (18). All pediatric patients were clinically diagnosed with AML, and all underwent abdominal US examination.

\section{Instruments}

The examinations were performed using an EPIQ7 color ultrasonic diagnostic instrument (Philips, USA) and Mylab70 color ultrasonic diagnostic instrument (Biosound Esaote, Italy). Two-dimensional US was performed to observe the location, size, number, shape, and echogenicity of the abdominal masses, and doppler US was performed to evaluate blood supply.

\section{Statistical analysis}

The cases age and gender, the clinical manifestation, brain MRI and CT findings and US findings including hepatic and renal masses were collected. We reviewed these data and analyzed.

\section{Results}

\section{Clinical characteristics}

The 12 pediatric patients, including 5 boys and 7 girls, ranged in age from 9 months to 13 years old. All of the patients had a history of epilepsy. Six patients $(50 \%)$ had facial angiofibromas, and $66.6 \%$ suffered from development retardation. The clinical profile of each patient is summarized in Table 1. 
Table 2 Abdominal US findings of eight children with TSC

\begin{tabular}{lccc}
\hline Case & Renal cyst (maximum diameter) & Hepatic nodules (maximum diameter) & Renal nodules (maximum diameter) \\
\hline 1 & $38 \mathrm{~mm}$ & None & None \\
2 & None & $10 \mathrm{~mm}$ & $4 \mathrm{~mm}$ \\
3 & None & None & $22 \mathrm{~mm}$ \\
4 & None & $15 \mathrm{~mm}$ & $18 \mathrm{~mm}$ \\
5 & $18 \mathrm{~mm}$ & $31 \mathrm{~mm}$ & $4 \mathrm{~mm}$ \\
6 & $2 \mathrm{~mm}$ & None & $13 \mathrm{~mm}$ \\
7 & None & None & $24 \mathrm{~mm}$ \\
8 & None & $10 \mathrm{~mm}$ & $4 \mathrm{~mm}$ \\
9 & $5 \mathrm{~mm}$ & None & None \\
11 & None & None & $7 \mathrm{~mm}$ \\
\hline
\end{tabular}

US, ultrasound; TSC, tuberous sclerosis complex.

\section{Brain MRI and CT findings}

The patients underwent brain MRI or CT examination, which revealed a scattered distribution of multiple hyperintense nodules in all cases, involving the ependyma of the lateral ventricle, basal ganglia, subventricular area, and body and triangular part of the lateral ventricle.

\section{US findings: hepatic and renal masses}

In terms of renal lesions, $83.3 \%(10 / 12)$ of patients had bilateral renal AML and 33.3\% (4/12) had renal cysts. In terms of hepatic masses, 5 liver AMLs were detected by abdominal US. The ultrasonographic distribution is shown in Table 2.

\section{Discussion}

In the present study, we investigated the abdominal ultrasonographic manifestations of 12 pediatric TSC patients. The results, as determined by non-invasive US, indicated a high prevalence of multisystem disorders, particularly in the kidneys. As many as $83 \%$ of patients were found to have co-existing renal AML and neural lesions. Interestingly, almost $41.6 \%$ of the pediatric patients had TSC-associated hepatic AML, which was previously classified as a less common complication, with an incidence of only $6 \%$ (9). The present study provided radiological evidence of complex-associated abdominal manifestations in pediatric TSC patients, and indicated the potential clinical management focus on renal and hepatic disorders for early prevention using ultrasonography.

Recent studies have advanced the understanding of genetic mutations in TSC (1), which are characterized as TSC1 and TSC2 mutations encoding hamartin and tuberin, respectively (3). Therapeutic treatments based on the TSCgenetic signaling pathway have been progressively tested in clinical trials in recent years (23-25). However, during genetic research progress, various clinical phenotypes of TSC are still reported, and the established underlying pathogenic mechanisms may not explain the specific TSC subtypes (1). These novel phenotypes include TSCassociated renal cell carcinoma (26), bilateral renal AML $(27,28)$, lung lymphangioleiomyomatosis (LAM) (29), and liver AML (6). Overall, this evidence demonstrates a lack of awareness of the complexities of TSC. The heterogeneity of TSC phenotypes represents a challenge in the clinical management of the disease, as tailored therapeutic decisions for TSC patients are suggested based on disease characteristics (30).

Abnormalities in other organs of pediatric patients may not be easily identified. The reasons for this are as follows: (I) the disorder usually begins in infancy and is asymptomatic before initial detection (28); (II) multiorgan abnormalities are unpredictable and attributable to variants in the 
Table 3 Diagnostic criteria according to the 2012 International Tuberous Sclerosis Complex Consensus Conference (18)

\begin{tabular}{ll}
\hline Major criteria & Minor criteria \\
\hline Cortical dysplasias (incl. tubers and cerebral white matter radial migration lines) & 'Confetti' skin lesions \\
SEN & Dental enamel pits $(>3)$ \\
SEGA & Intraoral fibromas $(\geq 2)$ \\
Cardiac rhabdomyoma & Multiple renal cysts \\
Hypomelanotic macules $(\geq 3$, at least 5 mm diameter) & Retinal achromatic patch \\
Angiofibromas ( $\geq 3$ ) or fibrous cephalic plaque & Nonrenal hamartomas \\
Ungual fibromas $(\geq 2)$ & \\
Shagreen patch & \\
AMLs $(\geq 2)$ & \\
LAM & \\
Multiple retinal hamartomas & \\
\hline
\end{tabular}

Definite diagnosis: two major diagnostic criteria or one major with greater than or equal two minor diagnostic criteria or the presence of a TSC1 or TSC2 mutation (of confirmed pathogenicity). Possible diagnosis: either one major diagnostic criterion or greater than or equal two minor diagnostic criteria. From: reference (18). SEN, subependymal nodules; SEGA, subependymal giant cell astrocytoma; AML, angiomyolipoma; LAM, lymphangioleiomyomatosis.

distribution, number, size, and location of lesions, leading to non-specific clinical syndromes (31); (III) pediatric patients have fewer imaging options than adults due to safety reasons, including radiation exposure caused by CT; and (IV) infantile clinical manifestations of TSC are not fully understood and could result in a missing or incorrect diagnosis. Therefore, in the present study, we aim to increase the awareness of complex clinical manifestations of children diagnosed with TSC by applying the US method.

According to the 2012 International TSC Complex Congress Group (Table 3), renal AMLs are the main feature of TSC, and non-renal hamartomas and multiple renal cysts are secondary features of TSC. Patients with at least two main features or one main feature and two minor features can be diagnosed as TSC (18). In the present study, $83.3 \%$ patients were diagnosed with renal AMLs, according to abdominal US findings, which were the most common renal manifestation in our cohort. This result is consistent with those of other studies, which reported renal AMLs in $50-80 \%$ of TSC patients $(28,32,33)$.

Ultrasonography revealed multiple hyperechoic nodules of various sizes in both kidneys with clear boundaries (Figure 1). Nodule hyperechogenicity is associated with internal components and the location of the mass and degree of interfacial interfaces. Therefore, nodules with a more superficial location and more adipose tissue have higher echogenicity, whereas those with a deeper location, larger size, and more blood vessels and muscular components have a relatively lower echo. In our cohort, the US features of these lesions were suggestive of fat-rich renal AML.

Fat-rich renal AMLs are usually characterized as having benign clinical behavior (34); however, the prognosis of TSC-associated renal AMLs is distinctly different from that of AMLs $(35,36)$, despite having rich adipose tissue, due to younger onset age, bilateral renal involvement, and progressive growth tendency (35). TSC-related renal AMLs grow at a rate of $1.25 \mathrm{~cm} /$ year with age, which is much higher than that of sporadic AML (0.19 cm/year) (35), and a significant increase in the risk of bleeding has been reported with those of a larger size $(\geq 3 \mathrm{~cm})(36,37)$.

When a mass is relatively large, it can present shortbranch or star-shaped blood flow signal on color doppler flow imaging (CDFI) inside the lesion. In the US images reviewed in the present study, the largest renal nodule detected had such typical blood flow distribution (Figure 2), suggesting a potential risk of rupture according to the nature of the AML in TSC patients (35). Therefore, pediatric TSC patients with bilateral hyperechoic renal nodules detected on US may need appropriate early clinical management, even at the asymptomatic clinical stage, despite a negative CDFI US result. 

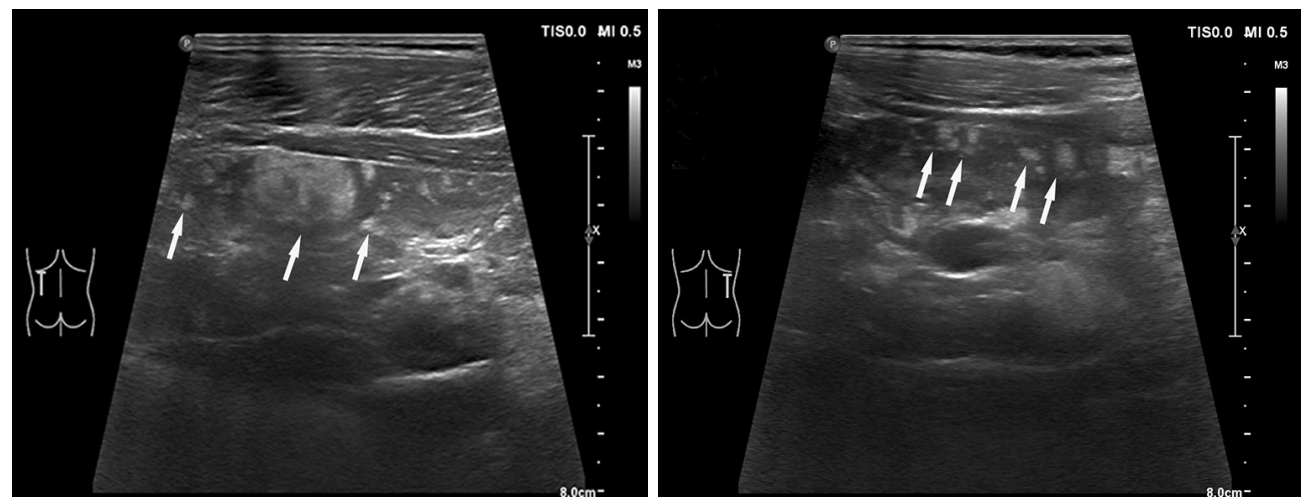

Figure 1 Multiple hyperechoic nodules (arrows) of different sizes in the kidneys.
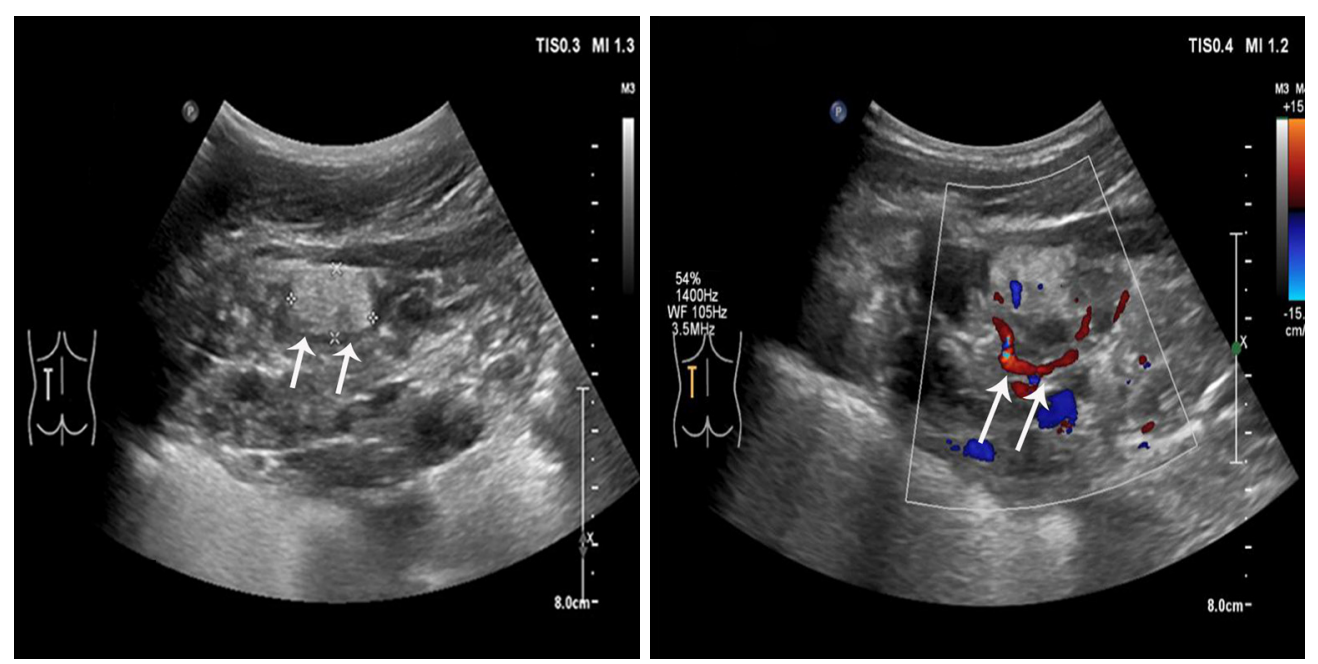

Figure 2 CDFI of blood flow signals in the form of short branches and star points (the arrows on the left shows the largest renal nodule and the arrows on the right shows the blood flow of the largest renal nodule). CDFI, color doppler flow imaging.

In addition to renal AML, multiple renal cysts are not uncommon in renal manifestations, occurring in 14-32\% of TSC patients (20). Similar to these figures, multiple renal cysts were detected in $33.3 \%$ of the patients in our study. The US features of our patients demonstrated multiple anechoic round or oval-shaped lesions with posterior acoustic enhancement and thin and smooth walls in both kidneys (Figure 3). No solid or well-vascularized components were detected inside the cystic nodules.

Simple renal cysts add no incremental prognostic value for TSC patients; however, they may have similar US features to early-stage, autosomal dominant polycystic kidney disease (ADPKD). ADPKD cysts progressively grow in size and number with age until they fill the renal parenchyma (38). Because the coding genes for ADPKD type 1 and TSC type 2 are both from a short segment of chromosome 16, TSC patients rarely have associated $\mathrm{ADPKD}$, which is called TSC2/ADPKD1 contiguous gene syndrome, which requires distinctly different management and has a different prognosis to renal simple cysts (39). Conversely, early-stage ADPKD should not be dismissed as renal cystic disease in TSC patients, and follow-up US screening for TSC patients with multiple renal cysts is needed.

In terms of US findings in the liver, multiple intrahepatic hyperechoic nodules were found in 5 cases in this study (41.6\% of the cohort). These nodules were characterized as having a clear nodular boundary and homogeneous echogenicity, indicating that they were benign (Figure 4 and Video 1). Multiple intrahepatic hyperechoic nodules co- 

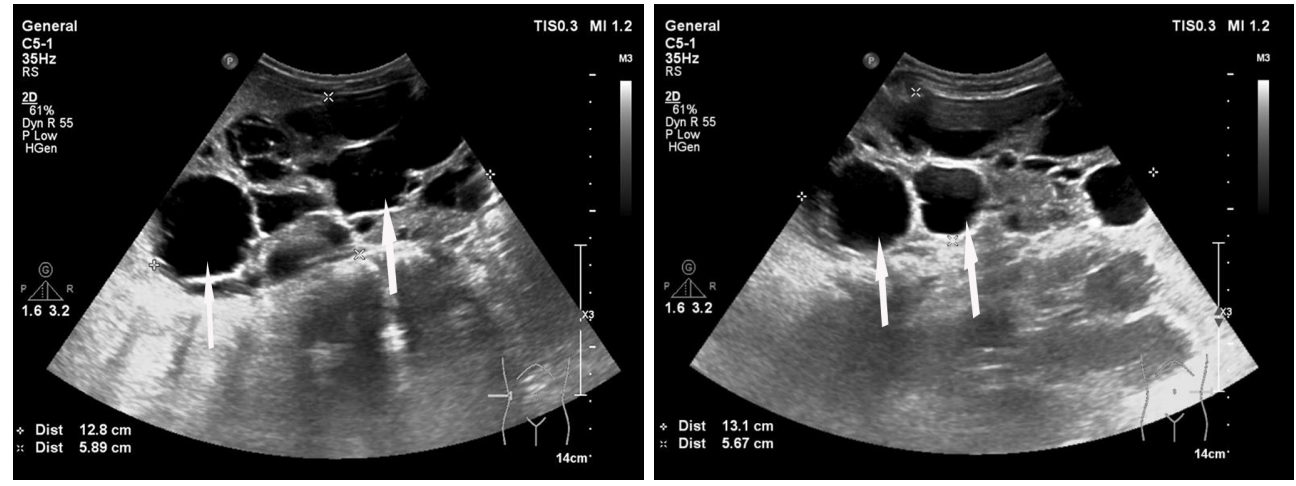

Figure 3 Multiple intrarenal cysts (arrows).
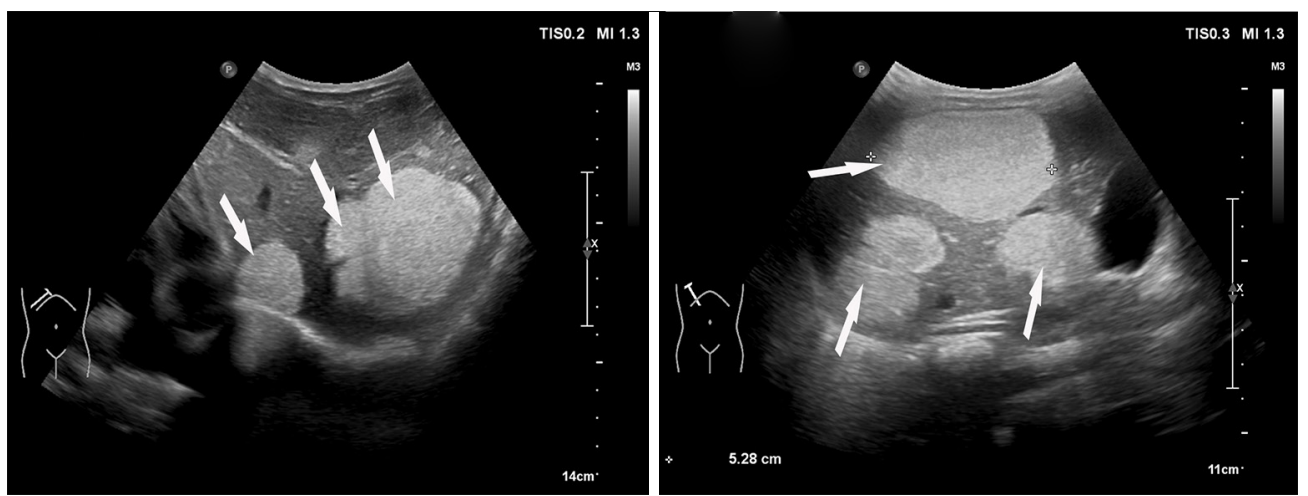

Figure 4 Multiple hyperechoic nodules in the liver (arrows).

occur with renal masses in TSC patients; therefore, these lesions are considered to be hepatic AMLs, as multiorgan hamartomas are a typical presentation of TSC based on the latest diagnostic criteria (18). As our cohort was small, the incidence of hepatic lesions was much higher than that of other studies, including that of Jóźwiak et al., who reported a prevalence of $14.9 \%$ (28/189) (6). However, both studies found hepatic and renal abnormalities to co-exist; this condition may be explained by TSC2 mutations (6).

Renal and hepatic AMLs are the dominant manifestations observed in pediatric TSC patients, except for the central neural system. AMLs have three main components (blood vessels, smooth muscles, and adipose tissues) and are usually diagnosed based on features, such as fatty tissue, on CT or MRI. However, the small size of lesions in children may increase the volume effect of images, and the true density of masses may be underestimated as a consequence (40). For US, high-resolution and high-frequency probes are capable of detecting lesions $<5 \mathrm{~mm}$ in diameter (Figure 5). Because children have thin abnormal walls with good penetration, US can identify small lesions with little difficulty. Therefore, for epilepsy with an unknown clinical cause or for pediatric patients with convulsions, spasms, mental retardation, facial angiofibromas, or skin discoloration, abdominal US of the kidneys and liver should be performed for the early diagnosis of TSC, before the detection of intracranial lesions with CT or MRI.

Radiation exposure in imaging is another common concern in pediatric investigations. However, for pediatric TSC patients, the identification of multisystem disorders and follow-up examinations are critical for clinical management (18). Although CT is recommended for TSC patients and is more accurate for diagnosis than US, there is the potential of accumulative radiation exposure, especially for follow-up purposes, which increases the subsequent risk of leukemia and brain tumors in the long term (41). Therefore, US is a good non-ionizing radiation tool for pediatric investigations. 


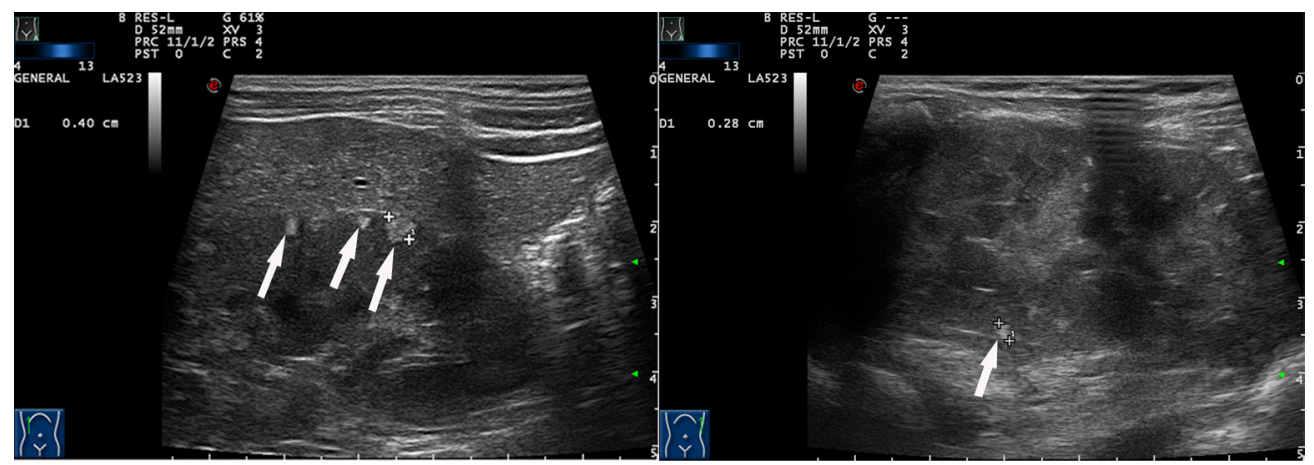

Figure 5 High-frequency probe detecting hyperechoic nodules $<5 \mathrm{~mm}$ (arrows) in the kidneys.

MRI is considered to be a safe, radiation-free technique for the examination of soft tissues. However, it is expensive, and has lower spatial resolution than CT and a relatively long scanning time. It is also difficult for children to remain still inside the scanner, particularly when the scanning time is long. Motion artifacts are not uncommon for pediatric MRI scanning. Based on image quality, MRI may not be suitable for the children who cannot cooperate.

Utilizing the use of imaging modalities is important for pediatric TSC patients with associated multisystem abnormalities, as invasive biopsy is not the primary option. Imaging is important for early identification, accurate diagnosis, imaging-guided clinical treatment, and follow-up in pediatric TSC patients. Because of the special nature of the cohort and disease, the optimal imaging modality is still unclear. In the present study, we reviewed the US imaging features of TSC patients, linking them with pathological mechanisms and clinical profiles, and compared these with other modalities. US is an ideal non-invasive tool for studying pediatric TSC patients, especially for these with coexisting abdominal abnormalities. Although the present study has the limitation of a small sample size and lack of follow-up clinical data, the agreement has confirmed by an expert consensus document in TSC. And the expert consensus document has suggested that pediatric TSC patients with small renal AMLs ( $<3 \mathrm{~mm}$ ) should undergo US follow-up examination every 1 or 2 years (42).

\section{Limitations}

The present study has some limitations. First, the number of patients included in the study was not sufficient; therefore, additional studies with a larger number of patients are required to confirm our preliminary findings. Second, the quality of a sonogram is dependent on the child's condition and the sonographer's skill, and these factors may have affected the results of the present study.

We clinically diagnosed 12 patients with AML according to the diagnostic criteria. Of these 12 patients, 3 underwent both abdominal US examination and abdominal CT or MRI examination. Abdominal CT or MRI confirmed our US diagnosis. However, the other 9 patients only underwent abdominal US examinations. Some children had repeated abdominal US examinations, but did not undergo CT or MRI examination. Some of the parents of the pediatric patients believed that the radiation dose was too high after CT examination, which was conducted 3-4 times a year, and considered the cost of MRI to be too high. For AMLs requiring long-term follow-up, the relatively cheap US examination is considered a suitable option. Furthermore, CT or MRI examination requires drug sedation for children who do not cooperate, and some parents may refuse to sedate their children. A clinician who diagnoses AML will perform a cranial MRI. However, CT and MRI are rarely used for abdominal examinations. Generally, simple and efficient US is used for examinations, and it is also used for follow-up. It is important to be able to detect lesions $<5 \mathrm{~mm}$ with high-frequency US; however, there is still a risk of misdiagnosis, as the detection of these lesions is based on the US doctor's clinical experience and skills, as well as regular follow-up.

TSC requires continued surveillance to monitor known manifestations and identify any potential new ones (18). The diagnosis and follow-up of TSC-associated abdominal abnormalities are based mainly on imaging studies (42). Abdominal US can provide easy, inexpensive, and noninvasive imaging-based diagnosis and monitoring of liver and renal lesions. Ultrasonography is useful as an initial 
approach for determining the presence of lesions whether they are solid or cystic. We hope that the findings of the present study will increase the awareness of radiologists and pediatricians regarding abdominal US in the examination of children with TSC. We recommend high-frequency US examination of the kidneys and liver in pediatric patients to improve the detection rate of small lesions and to confirm the results of the present study.

\section{Conclusions}

US is an important imaging tool for the diagnosis and follow-up of pediatric TSC patients. Abdominal abnormalities of pediatric TSC patients are not uncommon, particularly in the kidneys and liver. Familiarity with these ultrasonographic manifestations may improve disease diagnosis.

\section{Acknowledgments}

The authors thank Xiaoxiao Xie from the Department of Medical Imaging, and Miaomiao Lin from the Department of Pediatrics who contributed to data collection and conduct of the study.

Funding: None.

\section{Footnote}

Reporting Checklist: The authors have completed the STROBE reporting checklist. Available at http://dx.doi. org/10.21037/tp-20-150

Data Sharing Statement: Available at http://dx.doi. org/10.21037/tp-20-150

Conflicts of Interest: All authors have completed the ICMJE uniform disclosure form (available at http://dx.doi. org/10.21037/tp-20-150). The authors have no conflicts of interest to declare.

Ethical Statement: The authors are accountable for all aspects of the work in ensuring that questions related to the accuracy or integrity of any part of the work are appropriately investigated and resolved. The present retrospective study was conducted in accordance with the Declaration of Helsinki (as revised in 2013), and the study was approved by Institutional Review Board of the Second Affiliated Hospital of Wenzhou Medical University (No.
LCKY-230), and the requirement for informed consent from the patients was waived.

Open Access Statement: This is an Open Access article distributed in accordance with the Creative Commons Attribution-NonCommercial-NoDerivs 4.0 International License (CC BY-NC-ND 4.0), which permits the noncommercial replication and distribution of the article with the strict proviso that no changes or edits are made and the original work is properly cited (including links to both the formal publication through the relevant DOI and the license). See: https://creativecommons.org/licenses/by-nc-nd/4.0/.

\section{References}

1. Sahin M, Henske EP, Manning BD, et al. Advances and future directions for tuberous sclerosis complex research: recommendations from the 2015 Strategic Planning Conference. Pediatr Neurol 2016;60:1-12.

2. Davis PE, Filip-Dhima R, Sideridis G, et al. Presentation and diagnosis of tuberous sclerosis complex in infants. Pediatrics 2017;140:e20164040.

3. Curatolo P, Bombardieri R, Jozwiak S. Tuberous sclerosis. Lancet 2008;372:657-68.

4. Curatolo P, Moavero R, de Vries PJ. Neurological and neuropsychiatric aspects of tuberous sclerosis complex. Lancet Neurol 2015;14:733-45.

5. Wataya-Kaneda M, Uemura M, Fujita K, et al. Tuberous sclerosis complex: Recent advances in manifestations and therapy. Int J Urol 2017;24:681-91.

6. Jóźwiak S, Sadowski K, Borkowska J, et al. Liver angiomyolipomas in tuberous sclerosis complex-their incidence and course. Pediatr Neurol 2018;78:20-6.

7. Cook JA, Oliver K, Mueller RF, et al. A cross sectional study of renal involvement in tuberous sclerosis. J Med Genet 1996;33:480-4.

8. Korula S, Ekbote A, Kumar N, et al. Renal manifestations of tuberous sclerosis among children: an Indian experience and review of the literature. Clin Kidney J 2014;7:134-7.

9. Dabora SL, Jozwiak S, Franz DN, et al. Mutational analysis in a cohort of 224 tuberous sclerosis patients indicates increased severity of TSC2, compared with TSC1, disease in multiple organs. Am J Hum Genet 2001;68:64-80.

10. Jóźwiak S, Pedich M, Rajszys P, et al. Incidence of hepatic hamartomas in tuberous sclerosis. Arch Dis Child 1992;67:1363-5.

11. Fleury P, Smits N, van Baal S. The incidence of hepatic 
hamartomas in tuberous sclerosis. Evaluation by ultrasonography. Rofo 1987;146:694-6.

12. Fricke BL, Donnelly LF, Casper KA, et al. Frequency and imaging appearance of hepatic angiomyolipomas in pediatric and adult patients with tuberous sclerosis. AJR Am J Roentgenol 2004;182:1027-30.

13. Shepherd CW, Gomez MR, Lie JT, et al. Causes of death in patients with tuberous sclerosis. Mayo Clin Proc 1991;66:792-6.

14. Nelson CP, Sanda MG. Contemporary diagnosis and management of renal angiomyolipoma. J Urol 2002;168:1315-25.

15. Yu DT, Sheth KJ. Cystic renal involvement in tuberous sclerosis. Clin Pediatr (Phila) 1985;24:36-9.

16. Okada RD, Platt MA, Fleishman J. Chronic renal failure in patients with tuberous sclerosis. Association with renal cysts. Nephron 1982;30:85-8.

17. Huber C, Treutner KH, Steinau G, et al. Ruptured hepatic angiolipoma in tuberous sclerosis complex. Langenbecks Arch Chir 1996;381:7-9.

18. Krueger DA, Northrup H. Tuberous sclerosis complex surveillance and management: recommendations of the 2012 International Tuberous Sclerosis Complex Consensus Conference. Pediatr Neurol 2013;49:255-65.

19. Cockerell I, Guenin M, Heimdal K, et al. Renal manifestations of tuberous sclerosis complex: patients' and parents' knowledge and routines for renal follow-up - a questionnaire study. BMC Nephrol 2018;19:39.

20. Rakowski SK, Winterkorn EB, Paul E, et al. Renal manifestations of tuberous sclerosis complex: Incidence, prognosis, and predictive factors. Kidney Int 2006;70:1777-82.

21. Gimpel C, Avni EF, Breysem L, et al. Imaging of kidney cysts and cystic kidney diseases in children: an International Working Group Consensus Statement. Radiology 2019;290:769-82.

22. Flum AS, Hamoui N, Said MA, et al. Update on the diagnosis and management of renal angiomyolipoma. J Urol 2016;195:834-46.

23. Franz DN, Belousova E, Sparagana S, et al. Efficacy and safety of everolimus for subependymal giant cell astrocytomas associated with tuberous sclerosis complex (EXIST-1): a multicentre, randomised, placebo-controlled phase 3 trial. Lancet 2013;381:125-32.

24. McCormack FX, Inoue Y, Moss J, et al. Efficacy and safety of sirolimus in lymphangioleiomyomatosis. N Engl J Med 2011;364:1595-606.

25. Bissler JJ, Kingswood JC, Radzikowska E, et al.
Everolimus for angiomyolipoma associated with tuberous sclerosis complex or sporadic lymphangioleiomyomatosis (EXIST-2): a multicentre, randomised, double-blind, placebo-controlled trial. Lancet 2013;381:817-24.

26. Guo J, Tretiakova MS, Troxell ML, et al. Tuberous sclerosis-associated renal cell carcinoma: a clinicopathologic study of 57 separate carcinomas in 18 patients. Am J Surg Pathol 2014;38:1457-67.

27. Wang L, Ni D, Zhong L, et al. Familial genetic tuberous sclerosis complex associated with bilateral giant renal angiomyolipoma: a case report. Oncol Lett 2017;14:7099-106.

28. Kingswood JC, Belousova E, Benedik MP, et al. Renal angiomyolipoma in patients with tuberous sclerosis complex: findings from the TuberOus SClerosis registry to increase disease Awareness. Nephrol Dial Transplant 2019;34:502-8.

29. Cudzilo CJ, Szczesniak RD, Brody AS, et al. Lymphangioleiomyomatosis screening in women with tuberous sclerosis. Chest 2013;144:578-85.

30. Volpi A, Sala G, Lesma E, et al. Tuberous sclerosis complex: new insights into clinical and therapeutic approach. J Nephrol 2019;32:355-63.

31. Umeoka S, Koyama T, Miki Y, et al. Pictorial review of tuberous sclerosis in various organs. RadioGraphics 2008;28:e32.

32. Stillwell TJ, Gomez MR, Kelalis PP. Renal lesions in tuberous sclerosis. J Urol 1987;138:477-81.

33. Bernstein J, Robbins TO. Renal involvement in tuberous sclerosis. Ann N Y Acad Sci 1991;615:36-49.

34. Jinzaki M, Silverman SG, Akita H, et al. Renal angiomyolipoma: a radiological classification and update on recent developments in diagnosis and management. Abdom Imaging 2014;39:588-604.

35. Steiner MS, Goldman SM, Fishman EK, et al. The natural history of renal angiomyolipoma. J Urol 1993;150:1782-6.

36. Bissler J, Cappell K, Charles H, et al. Long-term clinical morbidity in patients with renal angiomyolipoma associated with tuberous sclerosis complex. Urology 2016;95:80-7.

37. Pedemonte JG, Degiovanni D, Pusterla D, et al. Angiomyolipoma and Lenk syndrome: case report. Actas Urol Esp 2008;32:850-4.

38. Lanktree MB, Chapman AB. New treatment paradigms for ADPKD: moving towards precision medicine. Nat Rev Nephrol 2017;13:750.

39. Back SJ, Andronikou S, Kilborn T, et al. Imaging features of tuberous sclerosis complex with autosomal-dominant 
polycystic kidney disease: a contiguous gene syndrome. Pediatr Radiol 2015;45:386-95.

40. Tchaprassian Z, Mognato G, Paradias G, et al. Renal angiomyolipoma in children: diagnositc difficulty in 3 patients. J Urol 1998;159:1654-6.

41. Pearce MS, Salotti JA, Little MP, et al. Radiation exposure from CT scans in childhood and subsequent risk of

Cite this article as: $\mathrm{Xu} \mathrm{Z,} \mathrm{Wu} \mathrm{J,} \mathrm{Xu} \mathrm{G,} \mathrm{Luo} \mathrm{H.} \mathrm{Abdominal}$ ultrasonographic manifestations in pediatric patients with tuberous sclerosis complex. Transl Pediatr 2020;9(6):757-767. doi: $10.21037 /$ tp-20-150 leukaemia and brain tumours: a retrospective cohort study. Lancet 2012;380:499-505.

42. Buj Pradilla MJ, Martí Ballesté T, Torra R, et al. Recommendations for imaging-based diagnosis and management of renal angiomyolipoma associated with tuberous sclerosis complex. Clin Kidney J 2017;10:728-37. 